\title{
The Physician-Patient Relationship- Perspectives After 40 Years of Family Practice
}

\section{A. Earl Mgebroff, $M D, P A$}

Thomas L. Delbanco, ${ }^{1}$ at Beth Israel Hospital in Boston, studied the physician-patient relationship from the patient's perspective. He found that patients want a competent physician who treats them with dignity and respect. Patients want to understand their sickness and how it will affect their lives. They want their physician to focus on their pain, physical discomfort, and functional disabilities. They are looking for a close, personal, ongoing relationship with a physician who cares about them and about what happens to them and their family. What these patients are looking for sounds very much like a family physician.

Delbanco's findings emphasize that we physicians need to reassess, reaffirm, and revitalize the physician-patient relationship and its centrality. I have learned a great deal from my patients during my years in practice; many patients have themselves exhibited qualities that would serve to enhance the physician-patient relationship. Several case histories illustrate five qualities that I believe are essential elements for any successful physician-patient relationship: integrity, positivism, mutuality, constancy, and spirituality.

\section{Integrity}

It has been said that the most important strategy for the individual physician is to reaffirm his or her personal and professional integrity. Integrity implies total honesty, trustworthiness, and reliability. Each treatment decision requires that the physician must first seek the patient's good before any consideration is given to the effect of that decision on the payment plan or the physician's income. Care must outweigh management.

Submitted, revised, 3 February 1997.

From the Yoakum Medical Clinic, Yoakum, Tex. Address reprint requests to A. Earl Mgebroff, MD, Yoakum Medical Clinic, PO Drawer 71, Yoakum, TX 77995.

Presented, in part, as the Fifth Annual Marcel Patterson Lecture in Family Medicine, University of Texas Medical Branch at Galveston, Tex, 23 June 1995.
In the early years of my practice, I had a patient who had terminal cancer. The patient's husband and family asked that I not tell her the true diagnosis, and in my inexperience and naiveté I agreed to help the family hide the truth from her. As she continued to lose weight and strength, she realized quite well what was happening to her, but she hid her knowledge from her family to please them. Her downhill course accelerated, and in those tired, suffering eyes that had once registered such confidence in me, I could see reflected a loss of that confidence and the unspoken question, "Doctor, I came to you in confidence. Why didn't you square with me?" That poor lady died in an atmosphere of dishonesty. She died with her family surrounding her but very alone.

I learned a valuable lesson from that experience. It is the patient who comes to us for care and it is the patient who should be our primary consideration. Often since then I have had to remind well-meaning relatives that it is Mom, Dad, or Aunt Ida who is my patient and to whom I owe my first allegiance. The negative impact of my lack of integrity in this case impressed upon me its importance in every physician-patient relationship. Without integrity there cannot be trust, and without trust there can be no enduring physician-patient relationship.

\section{Positivism}

By positivism, I mean a pervasive life stance, something that permeates one's entire being, uplifts, upholds, and imparts an unrelenting vitality and inner strength. Sir Luke Fildes' painting The Doctor depicts the physician sitting beside his patient, a young girl, spiritually and physically in contact with his patient and her family. In the early days of medicine, with meager knowledge and a paucity of effective pharmaceuticals, the physician had to rely to a great extent upon the old standbys of patient observation, calming reassurance, and the uplifting support of his presence, all administered through the enforcing vehicle of his comforting hands. 
What positivism he must have radiated through those hands, and eyes, and voice. Many times that unseen force was enough to make the difference in helping his patient recover.

Somewhere along the way we seem to have misplaced that quality of positivism. Words today have somehow lost their force as instruments of relief. Today patients seek reassurance through tests, not words. To beleaguered patients subjecting themselves to one additional $x$-ray examination, one more venipuncture or endoscopy, health becomes the proved absence of disease. The physician sitting opposite a patient must somehow radiate an aura of optimism to evoke in that patient the same sense of optimism that the physician knows is an essential ingredient of that patient's getting well.

I shared a long and meaningful physician-patient relationship with a sweet, gallant lady who taught me a great deal about how to live. She exhibited an incredible serenity in the face of hardship and more than her share of illness. Her medical history was like a condensed version of Harrison's: type 1 diabetes mellitus, coronary artery disease complicated by congestive heart failure and atrial fibrillation requiring long-term anticoagulation, and recurrent bouts of diverticulitis resulting in a perforated diverticulum and colon resection. She had breast cancer, gradually failing eyesight, and eventually total blindness as a result of diabetic retinopathy. Despite it all, she always had a big smile, a soft voice, a positive attitude. I respected her as a wonderful and warm human being, and her positive attitude was an example to all with whom she came in contact.

I have observed that when I have been able to create within the physician-patient relationship a pervasive and solid sense of positivism-not false hope but a genuine undercurrent of optimismthese patients have fared better than those overwhelmed by negative atritudes. ${ }^{2,3}$

\section{Mutuality}

Mutuality implies a sharing-a giving of one's self. It is a willingness to be open, to risk, to be vulnerable. It means communicating, really listening to what another person has to say, and it means bringing one's personhood into the relationship. When that is done faithfully, the result is understanding. And it is only through understanding that one can speak to the hearts of others with trust and clarity.

With our wonderful instruments of healing, we must guard against becoming so enamored with our own ingenuity that we forget these powerful tools are but complicated extensions of our hands. The hands at the controls should still be caring hands. The heady wine of near-miraculous cures and the simple distance our machines place us from our patient make it increasingly difficult for us as physicians to maintain rapport and a meaningful, caring relationship with our patient. I believe that it is the heritage of the family physician to maintain hand contact with the patient, to guide the patient through the maze of consultants and procedures, to uphold the basic precepts of the dignity of the individual and the sacredness of all life.

As an example of mutuality, let me tell you about a very special patient. She was only 8 years old when I discovered she had a brain tumor. Her medulloblastoma was treated with surgery, radiation, and chemotherapy, which left her with severe cerebellar ataxia. She lost her hair, her speech, and most of her memory and intelligence. This determined little girl struggled to relearn how to use her muscles-how to feed herself, how to walk, stand, talk, and do all the usual things you and I take for granted. She and I-her family and Ishared a great deal during those years. We really bared our souls, shared our personhood. I told them of my reactions to serious illness, my fears, my hopes, my expectations, my faith, and we compared notes.

To our surprise, this child reentered school and completed the remainder of her education without failing. But her problems were not over. She lost her mother to a malignancy and her father to a heart attack. She was devastated, but in her usual manner bounced back, returned to her classes, and graduated from high school. When, as president of the local school board, I stood on the football field on a clear May night and presented this brave girl with her diploma, it was one of the most emotional experiences of my life.

Mutuality does not always develop the breadth and depth it did in this case, but we can attempt to transmit to each of our patients our genuine, sincere concern for them as fellow human beings.

\section{Constancy}

Constancy implies not only duration, but also persistence, reliability, and availability. It means never deserting a patient, but always being ready to respond even if it requires self-sacrifice. Sometimes 
all we can do is show up, listen, and be as completely present as possible.

Constancy means not giving up on a patient, even when the case seems hopeless or when that patient is difficult. Alcoholics certainly qualify for the difficult category. A patient was an alcoholic who has not had a drink in nearly 20 years. When I first met him, he was what many townsfolk called an incurable alcoholic, a hopeless case. With the passage of years I learned a lot from him about alcoholism and the behavior of alcoholics. Little by little, he told me who he was, what made him tick. After climbing on and falling off the wagon numerous times, he reached his depths. He lost his job, he lost his health, his children would no longer come to visit him, his neighbors and friends avoided him. Only his loving wife stuck by him. She showed the meaning of constancy to me in a real way. Indeed, she was his salvation. One day in desperation, he finally turned to her and admitted, "Honey, I need help." With inpatient detoxification, ongoing care, and active membership in Alcoholics Anonymous, he was able to overcome his problem. Since then he has helped countless other alcoholics, some of whom have in turn become just as active; we now have a local network of nonpracticing alcoholics who are ready, willing, and eager to help anyone in need. Constancy-being there and never giving up on a patient-is an important dimension of the physician-patient relationship.

\section{Spirituality}

Despite the importance of faith in one's physician and in oneself, a time comes when this faith fails us. These are times when, having run on our own power as far as we can, we hit the proverbial wall; we must admit that in such times we have come to rely on a power outside ourselves.

As reluctant as we are to accept miracles, they do occur. I have witnessed more than a few. Let me tell you about my miracle baby. Her mother came to me because of her inability to become pregnant. Although she had lost a fallopian tube and ovary to surgery several years earlier, her remaining tube was patent and the ovary was functioning normally. Her husband had severe oligospermia. I referred the couple to a physician specializing in fertility problems, and after further studies and counseling, the couple decided to try artificial insemination using the husband's concentrated sperm.

There were repeated trips to the city, endless temperature charts, and failure after failure to conceive. Their disappointment was overcome by a strong and unswerving faith that if they persisted, something would happen. One night the patient developed severe pain in her lower abdomen. She had a ruptured tubal pregnancy, and at surgery the surgeon felt he had no alternative but to remove her remaining tube and ovary. She and her husband were crushed. She remained amenorrheic, however, and began to complain of nausea. Her quantitative human chorionic gonadotropin levels showed a rising titer compatible with a viable pregnancy. Sonography confirmed a normal intrauterine pregnancy. She had had a twin pregnancy, one in the tube, the other safely nestled in the uterus. Needless to say, I took extra good care of her, and she gave birth to a beautiful, healthy little girl.

Every patient we see believes in something. $\mathrm{Pa}$ tients' lives have a spiritual dimension that varies according to their own beliefs and value systems. We should respect that dimension of their being. Not only is it an important part of who they are, it can also be a powerful force in helping them to be healed or in giving them the inner strength to face serious illness and its consequences.

When the qualities of integrity, positivism, mutuality, constancy, and spirituality pervade the physician-patient relationship and blend into a unified whole, the result is an overarching quality called empathy. Empathy is not simply an affect, like sympathy. It is a skill that requires active listening, an articulate response, and the imagination to see oneself in another's shoes. If American medicine placed more value on empathy and communication skills, would it help solve some of the difficult moral quandaries confronting us? Perhaps. The point is that healing-real healing-is still best accomplished on a one-on-one basis. Each of us, alone in our isolation, needs someone to share our brokenness and suffering, who knows that death is not the worst enemy, that suffering can be redemptive, and that healing can only occur within community.

\section{References}

1. Delbanco TL. Enriching the doctor-patient relationship by inviting the patient's perspective. Ann Intern Med 1992;116:414-8.

2. Neimark PG, Schmidt JD, Jay H. A doctor discusses how to stay young and live longer. Chicago: Budlong Press, 1977.

3. Rosch PJ. Stress and cancer: how it may work for the patient as well as against. Consultant 1984;24(11): 73-6, 81, 84, passim. 